\title{
Genetic association of productive and reproductive traits with stayability in Nellore cattle: analysis using Bayesian models
}

\author{
E.C.A. Rizzo', F.R.A. Neto' ${ }^{2}$ I.D.P.S. Diaz², M.M. Dias², R.B. Costa ${ }^{2}$, \\ H.T. Ventura ${ }^{3,4}$, H.N. Oliveira ${ }^{2}$ and A.J.S. Falcão ${ }^{1}$ \\ ${ }^{1}$ Escola de Medicina Veterinária e Zootecnia, Universidade Federal do Tocantins, \\ Araguaína, TO, Brasil \\ 2Departamento de Zootecnia, Universidade Estadual de São Paulo "Júlio de \\ Mesquita Filho," Jaboticabal, SP, Brasil \\ ${ }^{3}$ Associação Brasileira dos Criadores de Zebu, Uberaba, MG, Brasil \\ ${ }^{4}$ Department of Biochemistry, College of Science, King Saud University, Riyadh, \\ Saudi Arabia \\ Corresponding author: E.C.A. Rizzo \\ E-mail: apathan@ksu.edu.sa / elianerizzootecnista@yahoo.com.br
}

Genet. Mol. Res. 14 (4): 14956-14966 (2015)

Received April 17, 2015

Accepted August 11, 2015

Published November 24, 2015

DOI http://dx.doi.org/10.4238/2015.November.24.3

ABSTRACT. We evaluated the genetic association of growth traits [weight adjusted to 205 days of age (W205), 365 days of age (W365), and 550 days of age (W550); weight gain between 205 days of age and 365 days of age (WG1) and between 365 days of age and 550 days of age (WG2)] and reproductive traits [age at first calving (AFC); first calving interval ( $\mathrm{FCl}$ )] with stayability in the herd (STAY), using Bayesian inference in linear and threshold models. We defined STAY as the probability of a cow calving three or more times before the age of 76 months, given that she had calved at least once. We assigned binary codes ( 0 , failure; 1 , success) to each female. We used a sire model for analysis and formed different contemporary groups for the investigated traits. We analyzed the results by applying a two-trait sire model that included STAY (threshold trait) and linear traits (W205, W365, W550, WG1, WG2, AFC, and FCl). We used 
Gibbs sampling to estimate variance components and heritabilities. In all the analyses, we found that the mean heritability estimates for STAY were of moderate magnitude (0.20-0.25). The mean heritabilities for W205, W365, W550, WG1, WG2, AFC, and FCl were $0.20,0.23,0.39,0.08,0.14,0.12$, and 0.11 , respectively. We observed wide variation in the posterior distributions of genetic correlations; however, with the exception of those obtained for the reproductive traits, the mean estimates were of low magnitude. Selection for WG2 can results in favorable correlated response in STAY.

Key words: Heritability; Longevity; Selection of females; Threshold model

\section{INTRODUCTION}

An increase in cow longevity reduces annual production costs derived from heifer replacement and involuntary culling. Consequently, higher selection intensities can be applied to female selection criteria in breeding programs.

Production during the life of a cow is of direct economic importance but is difficult to define. Moreover, selection for this trait is associated with a series of problems. First, the cow needs to leave the herd so that the trait is expressed. Therefore, the main problem related to the analysis of measures of longevity-associated traits such as the length of productive life of a cow in the herd is the presence of censoring, i.e., the recording of partial observations. Several animals of the contemporary groups that are being analyzed will remain in the herd throughout the study. Hence, the data obtained from these animals cannot be used in the analysis, and this leads to bias in the results.

Several mathematical expressions have been used to define traits that could be used to express the total production of a cow. These traits include stayability in the herd (STAY), number of calves produced, and calf weight (Lôbo et al., 1994, 2000; Eler et al., 2006). One of the traits most commonly used to represent the useful life of females is STAY, which is evaluated in dairy and beef cattle herds.

STAY is defined by some authors as the probability that a cow will survive to a specific age, given that it has the opportunity to reach this age (Hudson and Van Vleck, 1981; Marcondes et al., 2005). Other researchers define STAY as the fraction of progeny of a certain bull that is still alive at a particular age, given that these progeny are a part of a group that has had the opportunity to reach this age. According to Van Vleck (1980), the advantages of STAY are that this trait is easily measured and it represents the selection criteria of the breeder who eliminates cows based on low production. Another advantage is that STAY is expressed at a fixed age; hence, it is not necessary to wait for the animals to be culled from the herd before measuring the trait. However, because stayability is measured later in life than age at first calving (AFC) and first calving interval ( $F C l)$, its use as selection criteria could increase generation interval and reduce genetic progress on $\mathrm{AFC}$ and $\mathrm{FCl}$.

The use of STAY in genetic evaluations has a series of limitations owing to the binary nature of the observations. According to Smith and Allaire (1986), linear models-, which do not accommodate censored data-are also inadequate for the analysis of binomial data because of the violation of the assumption of normality. In contrast, threshold models for binary data have been used efficiently for decade (Rekaya et al., 2001; Silva et al., 2003).

According to Silva et al. (2003), STAY in beef cattle represents an indicator trait of reproductive capacity. The reason is that in beef cattle farming, cows are culled because of reproductive failure and not based on low productive capacity. STAY is currently used an indicator 
trait of reproductive capacity in various beef cattle breeding programs in Brazil. However, to the best of our knowledge, no previous studies have examined the association of this trait with other productive and reproductive traits, in order to indicate the effect of selection for STAY on other traits of economic importance or to identify an indicator trait of longevity.

In the present study, we evaluated the genetic association of growth and reproductive traits with STAY, using Bayesian inference in linear and threshold models.

\section{MATERIAL AND METHODS}

\section{Traits and data consistency}

The data used in this study refer to Nellore herds reared in the northern region of Brazil and were provided by the Brazilian Association of Zebu Breeders which is located in Uberaba - MG, Brazil [Associação Brasileira dos Criadores de Zebu (ABCZ)]. We studied the following traits: weight adjusted to 205 days of age (W205), 365 days of age (W365), and 550 days of age (W550); weight gain between standard ages [205-365 days (WG1) and 365-550 days (WG2)]; age at first calving (AFC) first calving interval (FCI); and STAY. We defined STAY as a binary variable, attributing a value of 1 to cows with at least three calvings before the age of 76 months and a value of 0 to cows with fewer than three calvings before the age of 76 months. According to Formigoni et al. (2002), three calvings cover the costs of breeding and rebreeding of a cow. We established a period of 76 months to enable the cow to reach three calvings, because the first calving generally occurs at 32 months of age. Only data obtained from females with STAY records were included in our analyses.

We analyzed the structure and consistency of the dataset using the Statistical Analysis System program (SAS, 2004). The environmental factors used for the formation of the contemporary groups varied according to the trait studied. For weights and weight gains, the contemporary groups were formed by animals born on the same farm, in the same year and season of birth, and reared under the same feeding regimen. For AFC and STAY, only animals born on the same farm and in the same year and season of birth were considered. For $\mathrm{FCl}$, animals were grouped according to cow's farm, year of birth and season of first calving. Contemporary groups with at least 10 animals and offspring of a single sire were maintained. In the case of STAY, contemporary groups showing no variation were excluded. For the remaining traits, animals with performance records having 3.5 standard deviations above or below the mean of their contemporary group were excluded. The descriptive statistics of the dataset used are shown in Table 1.

Table 1. Descriptive statistics of the dataset used for the combined analysis of STAY (T1) and linear traits (T2).

\begin{tabular}{lccccc}
\hline T2 & N (T1) & N (T2) & Mean (T2) & SD (T2) \\
\hline W205 & 8407 & 19,441 & $172.07 \mathrm{~kg}$ & $27.48 \mathrm{~kg}$ & P (0) \\
W365 & 7813 & 15,402 & $227.82 \mathrm{~kg}$ & $45.36 \mathrm{~kg}$ & $42.9 \%$ \\
W550 & 9834 & $278.88 \mathrm{~kg}$ & $47.16 \mathrm{~kg}$ & $42.7 \%$ \\
WG1 & 7452 & 15,514 & $55.33 \mathrm{~kg}$ & $32.92 \mathrm{~kg}$ & $43.5 \%$ \\
WG2 & 7813 & 9962 & $60.65 \mathrm{~kg}$ & $22.61 \mathrm{~kg}$ & $42.7 \%$ \\
AFC & 7452 & 49,174 & 1147 days & 138 days & $43.5 \%$ \\
FCl & 11,055 & 27,468 & 494 days & 113 days & $41.6 \%$ \\
\hline
\end{tabular}

$\mathrm{N}$, number of observations; SD, standard deviation; $\mathrm{P}(0)$, proportion of animals that did not achieve three calvings until 6 years of age; W205, weight adjusted to 205 days of age; W365, weight adjusted to 365 days of age; W550, weight adjusted to 550 days of age; WG1, weight gain between 205 days and 365 days of age; WG2, weight gain between 365 days and 550 days of age; $\mathrm{AFC}$, age at first calving; $\mathrm{FCl}$, first calving interval. 


\section{Genetic-quantitative analysis}

In the present study, we conducted two-trait analysis in a sire model that included STAY (threshold trait), growth traits (W205, W365, W550, WG1, and WG2), and reproductive traits (AFC and $\mathrm{FCl})$. The matrix representation of the analysis model is:

$$
\left[\begin{array}{c}
y_{S T A Y} \\
y_{\text {LINEAR }}
\end{array}\right]=\left[\begin{array}{cc}
X_{\text {STAY }} & 0 \\
0 & X_{\text {LINEAR }}
\end{array}\right]\left[\begin{array}{c}
b_{\text {STAY }} \\
b_{\text {LINEAR }}
\end{array}\right]+\left[\begin{array}{cc}
Z_{\text {STAY }} & 0 \\
0 & Z_{\text {LINEAR }}
\end{array}\right]\left[\begin{array}{c}
S_{\text {STAY }} \\
s_{\text {LINEAR }}
\end{array}\right]+\left[\begin{array}{c}
\varepsilon_{\text {STAY }} \\
\varepsilon_{\text {LINEAR }}
\end{array}\right] \quad \text { (Equation 1) }
$$

where $y, b, s$, and $\varepsilon$ are the vectors of observations, effects (contemporary groups), random sire effect, and random residual effect, respectively; and $X$ and $Z$, in this order, are the incidence matrices relating the effects to the observations.

We estimated variance and covariance components using Bayesian methods based on the marginal posterior distributions of the parameters. We considered the following a priori distributions: uniform for the effects of contemporary groups, Gaussian for sire and residual effects, and inverse Wishart distributions, which are inverse multivariate gamma distributions, for sire $(G)$ and residual $(R)(\mathrm{co})$ variance components.

The threshold model used for the analysis of STAY was based on the theory initially proposed by Sorensen (1996) and Korsgaard et al. (2003), using Bayesian inference through Gibbs sampling in single- and multi-trait models. In these models, it is assumed that the underlying scale shows a normal distribution, which can be described as:

$$
U \mid \theta \sim N\left(W \theta, I \sigma_{e}^{2}\right)
$$

where $U$ is the underlying variable vector of order $r ; \theta^{\prime}=\left(b^{\prime}, a^{\prime}\right)$ is the vector of the location parameters of order $s$ with $p$ fixed effects $(b)$ and $k$ random additive genetic values $(a)$; $W$ is a known incidence matrix of order $r \times s$; I is an identity matrix of order $r$, and $o_{e}^{2}$ is the residual variance. The variable in the underlying distribution is not observable, and therefore parameterization $\mathrm{o}_{\mathrm{e}}^{2}=1$ is generally adopted to obtain reliability in the likelihood function (Gianola and Sorensen, 2002).

Categorical traits are determined by non-observable continuous variables in the underlying scale and initial threshold values are established, where $\mathrm{t}_{1}<\mathrm{t}_{2}<\ldots<\mathrm{t}_{\mathrm{j}-1}$, with $\mathrm{t}_{0}=-\infty$ and $\mathrm{t}_{\mathrm{j}}=+\infty$, with $j$ being the number of categories. The conditional probability that the response variable, $y_{i}$, falls in category $\mathrm{j}(\mathrm{j}=0 ; 1)$ can be written as:

$$
P\left(y_{i}=0 \mid t, \theta\right)=P\left(U_{i}<t \mid t, \theta\right)=\Phi\left(\left(t-w_{i}^{\prime} \theta\right) / \sigma_{e}^{2}\right)
$$

where $y_{i}$ is the response variable for the $i^{\text {th }}$ observation; $t$ is the value of the threshold that defines the categories of the response; $U_{i}$ is the value of the underlying variable; $\Phi()$ is the cumulative distribution function of a standardized normal variate; $w_{i}^{\prime}$ is a row incidence vector that associate $\theta$ to the $\mathrm{i}^{\text {th }}$ observation.

The analyses were carried out using the THRGIBBSF90 program (Misztal, 2007), in which methods of Bayesian inference through the Gibbs sampler are implemented. The analysis was performed using a single chain of 400,000 samples, with a conservative burn-in period of 40,000 cycles and retention of a sample for every 10 iterations. Next, convergence of the Markov chains was 
confirmed using graphic (visual) inspection and the Geweke test (1992). Thus, descriptive statistics of the samples were obtained considering a stationary chain. The genetic parameters (heritabilities and genetic correlations) and breeding values were calculated vector by vector, and distributions were obtained for these parameters. In view of the possibility of obtaining asymmetrical posterior distributions of the parameters, the $95 \%$ highest posterior density intervals of the samples were calculated. Convergence diagnostics were performed using the Bayesian Output Analysis program (BOA) (Smith, 2005), available in the $\mathrm{R}$ Core Team programming package ( $\mathrm{R}$ Core Team, 2012).

\section{RESULTS}

The convergence diagnostics revealed that the burn-in period adopted was sufficient to obtain stationary chains; with the exception of one parameter, the z-scores were within the range of -1.96 to +1.96 in the Geweke test (Tables 2-4). Posterior densities and trace plots for adjusted weights, weight gains, and reproductive traits, are shown in Figures 1, 2, and 3, respectively. The null hypothesis for residual variance of WG1 was rejected in the Geweke test (Table 3); however, visual inspection of the sample sequence trace (Figure 2) showed that the chain could be considered stable even in this case.

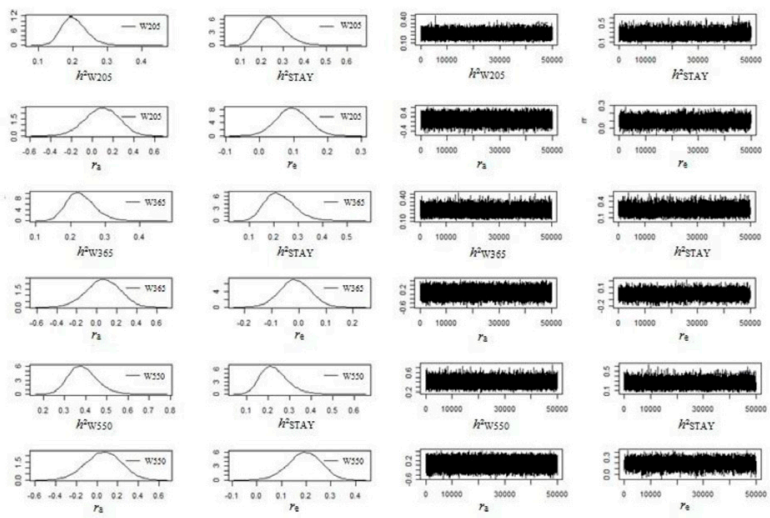

Figure 1. Posterior density (left) and trace plots (right) of heritabilities for weights adjusted for 205 days $\left(h^{2}{ }_{\text {w205 }}\right), 365$ days $\left(h^{2}{ }_{\text {W365 }}\right)$, and 550 days $\left(h_{\text {W550 }}^{2}\right.$ ), stayability $\left(h^{2}{ }_{\text {STAY }}\right)$, genetic correlation (ra), and residual correlation (re) for each weight.

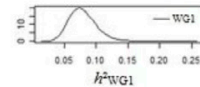

$h^{2} \mathrm{~W}$ G
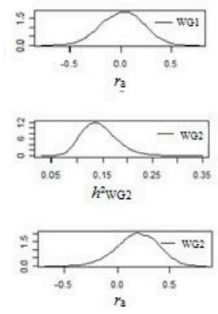

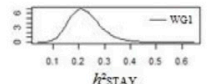

$h^{2} \mathrm{STAY}$
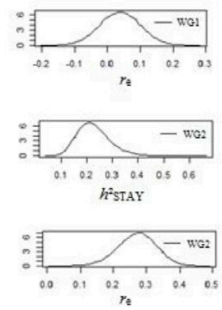
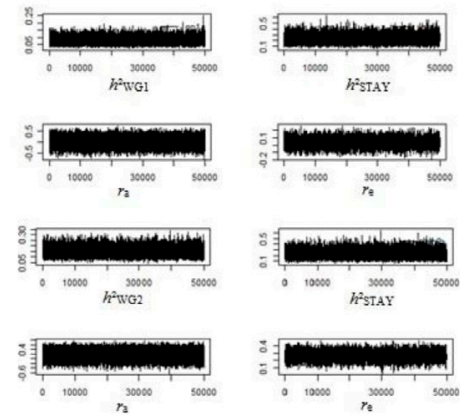

Figure 2. Posterior density (left) and trace plots (right) of heritabilities for weight gain between 205 and 365 days $\left(h_{\text {WG1 }}^{2}\right)$ and between 365 and 550 days $\left(h_{\text {WG2 }}^{2}\right)$, stayability $\left(h_{\text {STAY }}^{2}\right)$, genetic correlation (ra), and residual correlation (re) for each trait. 

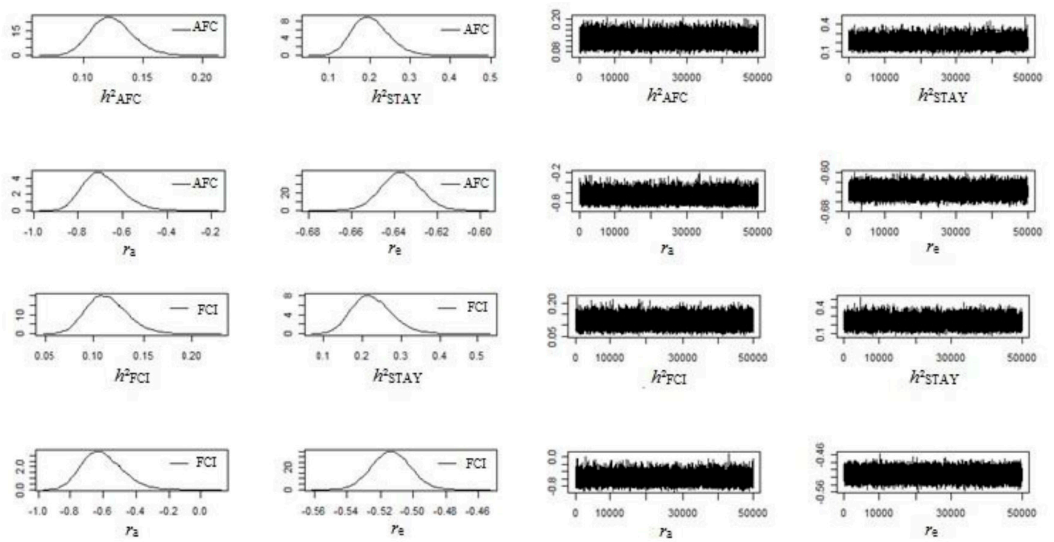

Figure 3. Posterior density (left) and trace plots (right) of heritabilities for age at first calving $\left(h_{\mathrm{AFC}}^{2}\right)$ and first calving interval $\left(h_{\mathrm{FCI}}^{2}\right)$, stayability $\left(h_{\text {STAY }}^{2}\right)$, genetic correlation (ra), and residual correlation (re) for each trait.

All the posterior distributions of the parameters tended to approach a normal distribution; however, the correlations showed wide highest posterior density intervals.

In all the analyses, the heritability estimates (Tables 2-4) for STAY were of moderate magnitude $(0.20-0.25)$.

Table 2. Posterior means, 95\% highest posterior density intervals (95HPD), and Geweke z-scores of the parameters estimated in two-trait analysis between stayability (STAY) and weights adjusted for 205 days (W205), 365 days (W365), and 550 days (W550) of age.

\begin{tabular}{|c|c|c|c|c|c|}
\hline \multirow[t]{2}{*}{ Weight } & \multirow[t]{2}{*}{ Parameter ${ }^{*}$} & \multirow[t]{2}{*}{ Mean } & \multicolumn{2}{|c|}{ 95HPD } & \multirow[t]{2}{*}{ Geweke } \\
\hline & & & Lower limit & Upper limit & \\
\hline \multirow[t]{8}{*}{ W205 } & $\sigma_{s 1}{ }^{2}$ & 0.07 & 0.03 & 0.11 & 0.19 \\
\hline & $\sigma_{s 3^{2}}$ & 22.32 & 14.86 & 30.35 & 0.69 \\
\hline & $\sigma_{e 1}^{2{ }^{2}}$ & 1.02 & 0.99 & 1.05 & 0.27 \\
\hline & $\sigma_{e 2}{ }^{2}$ & 413.82 & 404.90 & 421.90 & 1.12 \\
\hline & $h_{1}^{2}$ & 0.25 & 0.13 & 0.38 & 0.18 \\
\hline & $h_{2}^{2}$ & 0.20 & 0.14 & 0.27 & 0.67 \\
\hline & $\rho_{s}$ & 0.09 & -0.23 & 0.39 & 1.79 \\
\hline & $\rho_{r}^{s}$ & 0.09 & 0.004 & 0.19 & -0.45 \\
\hline \multirow[t]{8}{*}{ W365 } & $\sigma_{s 1}{ }^{2}$ & 0.06 & 0.03 & 0.09 & 0.37 \\
\hline & $\begin{array}{l}\sigma_{s 2}^{2} \\
\sigma_{s}^{2}\end{array}$ & 50.84 & 33.80 & 69.76 & -1.01 \\
\hline & $\sigma_{e 1}{ }^{2}$ & 1.02 & 0.99 & 1.05 & -1.49 \\
\hline & $\sigma_{\theta 2}{ }^{2}$ & 831.38 & 811.70 & 849.90 & 1.01 \\
\hline & $h_{1}^{2}$ & 0.23 & 0.12 & 0.35 & 0.41 \\
\hline & $h_{2}^{2}$ & 0.23 & 0.16 & 0.31 & -1.03 \\
\hline & $\rho_{s}$ & 0.07 & -0.26 & 0.37 & -0.38 \\
\hline & $\rho_{r}$ & -0.01 & -0.12 & 0.09 & -1.85 \\
\hline \multirow[t]{8}{*}{ W550 } & $\sigma_{s 1}{ }^{2}$ & 0.06 & 0.03 & 0.10 & 0.36 \\
\hline & $\begin{array}{l}{ }^{s 1}{ }^{2} \\
\sigma_{s}{ }^{2}\end{array}$ & 95.41 & 62.15 & 132.10 & -0.19 \\
\hline & $\sigma_{e 1}^{2}{ }^{2}$ & 1.03 & 0.99 & 1.06 & 0.56 \\
\hline & $\sigma_{e e^{2}}{ }^{2}$ & 886.30 & 859.80 & 911.30 & -0.38 \\
\hline & $h_{1}^{2}$ & 0.23 & 0.12 & 0.36 & 0.35 \\
\hline & $h_{2}^{2}$ & 0.39 & 0.26 & 0.52 & -0.17 \\
\hline & $\rho_{s}$ & 0.06 & -0.27 & 0.38 & -1.72 \\
\hline & $\rho_{r}^{s}$ & 0.19 & 0.06 & 0.32 & 1.43 \\
\hline
\end{tabular}

${ }^{*} \sigma_{s 1}{ }^{2}$, sire variance for STAY; $\sigma_{s 2}{ }^{2}$, sire variance for the weight analyzed; $\sigma_{e 1}{ }^{2}$, residual variance for STAY; $\sigma_{e 2}{ }^{2}$, residual variance for the weight analyzed; $h_{1}{ }^{2}$, heritability for STAY; $h_{2}^{2}$, heritability for the weight analyzed; $\rho_{s}$, genetic correlation; $\rho_{r}$, residual correlation. 
Table 3. Posterior means, 95\% highest posterior density intervals (95HPD), and Geweke z-scores of the parameters estimated in two-trait analysis between stayability (STAY) and weight gain between the adjusted ages of 205 and 365 days (WG1) and 365 and 550 days (WG2).

\begin{tabular}{|c|c|c|c|c|c|}
\hline \multirow[t]{2}{*}{ Weight gain } & \multirow[t]{2}{*}{ Parameter } & \multirow[t]{2}{*}{ Mean } & \multicolumn{2}{|c|}{ 95HPD } & \multirow[t]{2}{*}{ Geweke } \\
\hline & & & Lower limit & Upper limit & \\
\hline \multirow[t]{8}{*}{ WG1 } & $\sigma_{s 1}{ }^{2}$ & 0.06 & 0.039 & 0.09 & 1.39 \\
\hline & $\begin{array}{l}s_{s 1} \\
\sigma_{s 2}^{2}\end{array}$ & 9.23 & 4.74 & 14.15 & -0.74 \\
\hline & $\sigma_{e 1}^{2}{ }^{2}$ & 1.02 & 0.99 & 1.05 & -0.34 \\
\hline & $\sigma_{e 2}^{21}$ & 456.17 & 445.50 & 466.40 & 2.29 \\
\hline & $h_{1}^{22}$ & 0.23 & 0.11 & 0.35 & 1.41 \\
\hline & $h_{2}^{2}$ & 0.08 & 0.04 & 0.12 & -0.77 \\
\hline & $\rho_{s}$ & 0.02 & -0.38 & 0.41 & -0.14 \\
\hline & $\rho_{r}^{s}$ & 0.04 & -0.08 & 0.16 & 1.22 \\
\hline \multirow[t]{8}{*}{ WG2 } & $\sigma_{s 1}^{2}$ & 0.06 & 0.03 & 0.09 & -0.54 \\
\hline & $\sigma_{s 2}^{2}$ & 7.49 & 4.09 & 11.32 & 0.96 \\
\hline & $\sigma_{e 1}{ }^{2}$ & 1.03 & 0.99 & 1.06 & 0.08 \\
\hline & $\sigma_{e 2}^{2}$ & 199.08 & 193.30 & 204.70 & 1.85 \\
\hline & $h_{1}^{22}$ & 0.23 & 0.11 & 0.35 & -0.53 \\
\hline & $h_{2}^{2}$ & 0.14 & 0.08 & 0.22 & 0.90 \\
\hline & $\rho_{s}^{2}$ & 0.19 & -0.19 & 0.55 & 0.66 \\
\hline & $\rho_{r}$ & 0.27 & 0.16 & 0.39 & 0.14 \\
\hline
\end{tabular}

${ }^{*} \sigma_{s 1}{ }^{2}$, sire variance for STAY; $\sigma_{s 2}{ }^{2}$, sire variance for the weight gain analyzed; $\sigma_{e 1}{ }^{2}$, residual variance for STAY; $\sigma_{e 2}{ }^{2}$, residual variance for the weight gain analyzed; $h_{1}{ }^{2}$, heritability for STAY; $h_{2}{ }^{2}$, heritability for the weight gain analyzed; $\rho_{s}$, genetic correlation; $\rho_{r}$, residual correlation.

The posterior means of the variance components and genetic parameters are shown in Table 2 (adjusted weights), Table 3 (weight gains), and Table 4 (AFC and FCI). The mean heritabilities for W205, W365, and W550 were $0.20,0.23$, and 0.39 , respectively. The mean heritabilities for weight gains were of low magnitude (WG1, 0.08; WG2, 0.14) (Table 3). Moreover, the mean estimates of 0.12 and 0.11 obtained for AFC and FCl, respectively (Table 4) were considered low.

Table 4. Posterior means, 95\% highest posterior density intervals (95HPD), and Geweke z-scores of the parameters estimated in two-trait analysis between stayability (STAY) and the two investigated reproductive traits, namely, age at first calving (AFC) and first calving interval (FCI).

\begin{tabular}{|c|c|c|c|c|c|}
\hline \multirow[t]{2}{*}{ Reproductive trait } & \multirow[t]{2}{*}{ Parameter } & \multirow[t]{2}{*}{ Mean } & \multicolumn{2}{|c|}{ 95HPD } & \multirow[t]{2}{*}{ Geweke } \\
\hline & & & Lower limit & Upper limit & \\
\hline \multirow[t]{8}{*}{ AFC } & $\sigma_{s 1}^{2}$ & 0.05 & 0.03 & 0.08 & -0.89 \\
\hline & $\sigma_{s 2}^{s}{ }^{2}$ & 427.19 & 314.30 & 553.30 & -0.79 \\
\hline & $\begin{array}{l}\sigma_{e 12}{ }^{2} \\
\sigma_{2}\end{array}$ & 1.01 & 0.99 & 1.03 & 1.26 \\
\hline & $\sigma_{e e^{2}}{ }^{2}$ & 13,361 & 13,180 & 13,520 & 1.81 \\
\hline & $h_{1}^{22}$ & 0.20 & 0.12 & 0.29 & -0.89 \\
\hline & $h_{2}^{2}$ & 0.12 & 0.09 & 0.16 & -0.85 \\
\hline & $\rho_{s}$ & -0.69 & -0.85 & -0.51 & 0.47 \\
\hline & $\rho_{r}$ & -0.64 & -0.65 & -0.62 & 0.29 \\
\hline \multirow[t]{8}{*}{$\mathrm{FCl}$} & $\sigma_{s 1}{ }^{2}$ & 0.06 & 0.034 & 0.090 & -1.14 \\
\hline & $\sigma_{s 2}^{s i}$ & 251.88 & 165.90 & 342.90 & -0.05 \\
\hline & $\sigma_{s 2}{ }^{2}$ & 1.02 & 0.99 & 1.04 & -0.73 \\
\hline & $\sigma_{e 2}^{e}{ }^{2}$ & 8628 & 8476 & 8777 & -0.65 \\
\hline & $h_{1}^{22}$ & 0.23 & 0.13 & 0.33 & -1.13 \\
\hline & $h_{2}^{2}$ & 0.11 & 0.07 & 0.15 & -0.04 \\
\hline & $\rho_{s}$ & -0.60 & -0.83 & -0.36 & 0.19 \\
\hline & $\rho_{r}^{s}$ & -0.51 & -0.54 & -0.49 & 1.03 \\
\hline
\end{tabular}

${ }^{*} \sigma_{s 1}{ }^{2}$, sire variance for STAY; $\sigma_{s 2}{ }^{2}$, sire variance for the reproductive trait analyzed; $\sigma_{\theta 1}{ }^{2}$, residual variance for STAY; $\sigma_{\theta 2}{ }^{2}$, residual variance for the reproductive trait analyzed; $h_{1}{ }^{2}$, heritability for STAY; $h_{2}{ }^{2}$, heritability for the reproductive trait analyzed; $\rho_{s}$, genetic correlation; $\rho_{r}$, residual correlation. 


\section{DISCUSSION}

In the present study, all the posterior distributions of the parameters (Figures 1-3) tended to approach a normal distribution. However, the correlations showed wide highest posterior density intervals; hence, conclusions about these parameters must be drawn with caution. According to Lynch (1999), in comparison with univariate parameters, genetic correlations are particularly difficult to estimate because they require accurate estimates of the parameters of which they are functions.

In all the analyses, the heritability estimates (Tables 2-4) for STAY were of moderate magnitude $(0.20-0.25)$. These results suggest that a considerable part of genetic variation can be attributed to the average effects of genes, and this enables genetic gains to be obtained through selection. Similar heritability estimates have been reported in previous studies evaluating data obtained from Nellore cattle. Silva et al. (2006) determined an estimate of 0.22 . Melis et al. (2007) obtained heritabilities of $0.25,0.22$, and 0.28 for STAY at 5 years of age, 6 years of age, and 7 years of age, respectively. However, Buzanskas et al. (2010) reported a lower heritability (0.03) for this trait. This wide range in heritability estimates can be attributed to the different models used (sire or animal model) or the different definitions of STAY adopted, as well as to the different genetic constitutions of the populations studied.

The heritabilities for W205, W365, and W550 were $0.20,0.23$, and 0.39 , respectively. An increasing trend in heritability was previously observed in longitudinal studies of weights (Albuquerque and Meyer, 2001; Boligon et al., 2010). The heritabilities obtained in our present study are similar to those reported by Giannotti et al. (2005) for weights from birth to 550 days of age (0.23-0.31). However, they are lower than those reported by Siqueira et al. (2003), who analyzed weights at different ages (120, 455, and 550 days) and estimated heritabilities ranging from 0.29 to 0.58 for these traits. Faria et al. (2007) obtained higher heritability estimates for weights at 365 days (0.49) and 450 days (0.52) of age.

In the present study, the mean heritabilities for weight gains were of low magnitude (WG1, 0.08; WG2, 0.14) (Table 3). These estimates are lower than those obtained by Paneto et al. (2002) for Nellore cattle, using the REML method in single-trait analysis. These authors estimated heritabilities for WG120-240, WG240-365, WG365-455, and WG455-550 of 0.32, 0.16, 0.21, and 0.23 , respectively. However, the heritability for WG2 obtained in the present study is higher than those reported by Cucco (2008) for Brown Swiss cattle-0.12 (WG120-205), 0.12 (WG205-365), 0.13 (WG365-450), and 0.05 (WG450-365).

The heritability for AFC (0.12) obtained in the present study is similar to those reported by Dias et al. (2004), Silva et al. (2005), and Boligon et al. (2007, 2008) for Nellore cattle. Reproductive traits measured in Nellore females were previously reported to show low heritabilities, because these traits are strongly influenced by environmental factors and non-additive genetic effects. However, heritability estimates for AFC of moderate to high magnitude-ranging from 0.28 to 0.40 have been demonstrated (Mercadante et al., 2000; Bertazzo et al., 2004; Faria et al., 2008).

The heritability for $\mathrm{FCl}$ obtained in the present study was 0.11 and was considered low. On the other hand, Campello et al. (1999) and Silveira et al. (2004) studied calving intervals considering various measures per animal and estimated moderate and high coefficients of heritability $(0.32$ and 0.42, respectively). According to these authors, low coefficients of heritability are obtained when only the $\mathrm{FCl}$ or $\mathrm{FCls}$ are evaluated; the main reason is that young cows are more vulnerable to nutritional stress, and this impairs the identification of genetic differences. The traits AFC and $\mathrm{FCl}$ are generally of fundamental importance for the productivity of a herd. Gains in these traits obtained through genetic improvement will be permanent, and this justifies investment in the selection of genetically superior animals. 
We observed wide variation in the posterior distributions of genetic correlations between STAY and the other investigated traits (Figures 1-3); however, with the exception of those obtained for the reproductive traits, the mean estimates were of low magnitude. Values indicating a low association between weight and longevity traits have been reported previously. Buzanska et al. (2010) determined a genetic correlation of -0.09 between STAY and weight at 420 days of age in Canchim cattle. Silva et al. (2006) reported a positive genetic correlation (0.15) between STAY and weight at 550 days of age in Nellore cattle.

Based on the definition of STAY, the negative association of AFC and FCI with STAY is not surprising; in other words, the earlier an animal initiates breeding and the shorter its calving intervals, the higher will be the probability of success (at least three calvings before the age of 6 years). Silva (2012) obtained values of the same order of magnitude for Gyr cattle, by applying two different definitions of STAY at 48 months $(-0.55)$ and 60 months of age $(-0.54)$. However, contrary to the present study, the author reported positive correlations between STAY and FCl; this discrepancy was probably caused by the different definitions of STAY used.

Considering the magnitude of heritability for STAY obtained in the present study, genetic gain by direct selection would be expected. However, this trait is measured at an advanced age, and therefore the annual genetic gain may be compromised because of an increase in the generation interval. Hence, an alternative means of genetic gain would be indirect selection through traits that are measured at younger ages, and which are correlated with STAY. Given the genetic correlations, the most appropriate option for obtaining correlated gain would be to select animals for AFC-even if the accuracy of selection is lower-based on the magnitude of heritability. However, different definitions of criteria for the cow's initiation of breeding exist on different farms, and therefore the use of AFC as a selection criterion must be treated with caution. Furthermore, AFC is obtained earlier than STAY but is measured only after the animals have initiated breeding. Moreover, this trait is only expressed in females.

Most genetic breeding programs apply weight traits as selection criteria, and therefore the use of W550 and WG2 would be a more viable option. First, both traits are observed at younger ages than AFC and therefore they may contribute to a decrease in the generation interval. Considering the factors that influence correlated genetic gain, selection for WG2 would be more interesting based on the higher genetic correlation with STAY. However, W550 presents higher heritability, and therefore this trait would permit higher gains owing to the greater accuracy of selection.

\section{Conflicts of interest}

The authors declare no conflict of interest.

\section{ACKNOWLEDGMENTS}

The authors thank the Associação Brasileira dos Criadores de Zebu (ABCZ) for providing the dataset and Coordenação e Aperfeiçoamento de Pessoal de Nível Superior (CAPES) for financial support.

\section{REFERENCES}

Albuquerque LG and Meyer K (2001). Estimates of covariance functions for growth from birth to 630 days of age in Nelore cattle. J. Anim. Sci. 79: 2776-2789.

Bertazzo RP, Freitas RTF, Gonçalves TM, Pereira IG, et al. (2004). Parâmetros genéticos de longevidade e produtividade de fêmeas da raça Nelore. Rev. Bras. Zootec. 33: 1118-1127. 
Boligon AA, Albuquerque LG, Mercadante MEZ and Lôbo RB (2010). Study of relations among age at first calving, average weight gains and weights from weaning to maturity in Nellore cattle. Rev. Bras. Zootec. 39: 746-751.

Boligon AA, Albuquerque LG and Rorato PRN (2008). Associações genéticas entre pesos e características reprodutivas em rebanhos da raça Nelore. Rev. Bras. Zootec. 37: 596-601.

Boligon AA, Rorato PRN and Albuquerque LG (2007). Correlações genéticas entre medidas de perímetro escrotal e características produtivas e reprodutivas de fêmeas da raça Nelore. Rev. Bras. Zootec. 36: 565-571.

Buzanskas ME, Grossi DA, Baldi F, Barrozo D, et al. (2010). Genetic associations between stayability and reproductive and growth traits in Canchim beef cattle. Livest. Sci. 132: 107-112.

Campello CC, Martins Filho R and Lôbo RNB (1999). Intervalo de partos e fertilidade real em vacas nelore no estado do Maranhão. Rev. Bras. Zootec. 28: 474-479.

Cucco DC (2008). Estimativa de parâmetros genéticos para características de crescimento e perímetro escrotal na raça Pardo Suiç̧o Corte. Master's thesis, Faculdade de Zootecnia e Engenharia de Alimentos, Universidade Estadual de São Paulo, Pirassununga.

Dias LT, El Faro L and Albuquerque LG (2004). Estimativas de herdabilidade para idade ao primeiro parto de novilhas da raça Nelore. Rev. Bras. Zootec. 33: 97-102.

Eler JP, Ferraz JBS, Balieiro JCC, Mattos EC, et al. (2006). Genetic correlation between heifer pregnancy and scrotal circumference measured at 15 and 18 months of age in Nellore cattle. Genet. Mol. Res. 5: 569-580.

Faria CU, Magnabosco CU, Albuquerque LG, Los Reyes A, et al. (2008). Abordagem bayesiana e freqüentista em análise genética tricarácter para crescimento e reprodução de bovinos Nelore. Ciênc. Anim. Bras. 9: 598-607.

Faria CU, Magnabosco CU, Reyes A, Lôbo RB, et al. (2007). Bayesian inference in a quantitative genetic study of growth traits in Nelore cattle (Bos indicus). Genet. Mol. Biol. 30: 545-551.

Formigoni IB, Silva JAIIV, Brumatti RC, Ferraz JBS, et al. (2002). Economic aspects of stayability as selection criterion in beef cattle industry in Brazil. Proceedings of the $7^{\text {th }}$ World Congress on Genetics Applied to Livestock Production, Montpellier, CD-ROM. Section 2, Communication 02-62.

Geweke J (1992). Evaluating the accuracy of sampling-based approaches to the calculation of posterior moments. In: Bayesian Statistics. 4th edn. (Bernardo JM, Berger JO, Dawid AP, and Smith AFM, eds.). Oxford University Press, New York, 169-193.

Giannotti JDG, Packer IU and Mercadante MEZ (2005). Meta-análise para estimativas de herdabilidade para características de crescimento em bovinos de corte. Rev. Bras. Zootec. 34: 1173-1180.

Gianola D and Sorensen D (2002). Likelihood, Bayesian, and MCMC methods in quantitative genetics. 2nd edn. Statistics for Biology and Health. Springer-Verlag, New York.

Hudson GFS and Van Vleck LD (1981). Relationship between production and stayability in Holstein cattle. J. Dairy. Sci. 64: 2246-2250.

Korsgaard IR, Lund MS, Sorensen D, Gianola D, et al. (2003). Multivariate Bayesian analysis of Gaussian, right censored Gaussian, ordered categorical and binary traits using Gibbs sampling. Genet. Sel. Evol. 35: 159-183.

Lôbo RNB, Madalena FE and Vieira AR (2000). Means of published genetic parameter estimates for cattle raised on tropical climate. Anim. Breed. Abstr. 68: 433-462.

Lôbo RB, Reyes A, Ferraz JBS, Bezerra MEZ, et al. (1994). Bivariate animal model analysis of growth weights and scrotal circumference of Nellore cattle in Brazil. In: World Congress on Genetics Applied to Livestock Production, 5, Guelph, 199-202.

Lynch M (1999). Estimating genetic correlations in natural populations. Genet. Res. 74: 255-264.

Marcondes CR, Paneto JCC, Bezerra LAF and Lôbo RB (2005). Estudo de definição alternativa da probabilidade de permanência no rebanho para a raça Nelore. Rev. Bras. Zootec. 34: 1563-1567.

Melis MH Van, Eler JP, Oliveira HN, Rosa GJM, et al. (2007). Study of stayability in Nellore cows using a threshold model. J. Anim. Sci. 85: 1780-1786.

Mercadante MEZ, Lôbo RB and Oliveira HN (2000). Estimativas de (co)variâncias entre características de reprodução e de crescimento em fêmeas de um rebanho Nelore. Rev. Bras. Zootec. 29: 997-1004.

Misztal I (2007). BLUPF90 family of programs. Available at http://nce.ads.uga.edu/ ignancy/ newprograms.html.

Paneto JCC, Lemos DC, Bezerra LAF, Martins Filho R, et al. (2002). Estudo de características quantitativas de crescimento dos 120 aos 550 dias de idade em gado Nelore. Rev. Bras. Zootec. 31: 668-674.

R Core Team (2012). R: A language and environment for statistical computing. R Foundation for Statistical Computing, Vienna, Austria. Available at http://www.R-project.org/.

Rekaya R, Weigel KA and Gianola D. (2001). Threshold model for misclassified binary responses with applications to animal breeding. Biometrics 57: 1123-1129.

SAS Institute Inc. (2004). SAS OnlineDoc ${ }^{\circledR}$ 9.1.3. SAS Institute Inc., Cary.

Silva JAIIV, Dias LT and Albuquerque LG (2005). Estudo genético da precocidade sexual de novilhas em um rebanho Nelore. Rev. Bras. Zootec. 34: 1568-1572. 
Silva JAIIV, Eler JP, Ferraz JBS, Golden BL, et al. (2003). Heritability estimate for stayability in Nelore cows. Livest. Prod. Sci. 79: 97-101.

Silva JAIIV, Formigoni IB, Eler JP and Ferraz JBS (2006). Genetic relationship among stayability, scrotal circumference and post-weaning weight in Nelore cattle. Livest. Sci. 99: 51-59.

Silva RMO (2012). Estimativas de parâmetros genéticos para habilidade de permanência no rebanho e suas associações com características de interesse econômico em vacas da raça Gir Leiteiro. Master's thesis, Universidade Federal de Alagoas, Rio Largo.

Silveira JC, McManus C, Mascioli AS, Silva LOC, et al. (2004). Fatores ambientais e parâmetros genéticos para características produtivas e reprodutivas em um rebanho nelore no estado do Mato Grosso do Sul. Rev. Bras. Zootec. 33: $1432-1444$.

Siqueira RLPG, Oliveira JA, Lôbo RB, Bezerra LAF, et al. (2003). Análise da variabilidade genética aditiva de características de crescimento na raça Nelore. Rev. Bras. Zootec. 32: 99-105.

Smith BJ (2005). Bayesian Output Analysis program (BOA). Version 1.1 User's Manual. Available at [http://www.public-health. uiowa.edu/boa/BOA.pdf].

Smith SP and Allaire FR (1986). Analysis of failure times measured on dairy cows: Theoretical considerations in animal breeding. J. Dairy. Sci. 69: 217-227.

Sorensen D (1996). Gibbs sampling in quantitative genetics. Intern Report, Danish Institute of Animal Science, Department of Breeding and Genetics, Tjele.

Van Vleck LD (1980). Stayability evaluation as a categorical trait and by considering other traits. J. Dairy. Sci. 63: $1172-1180$. 